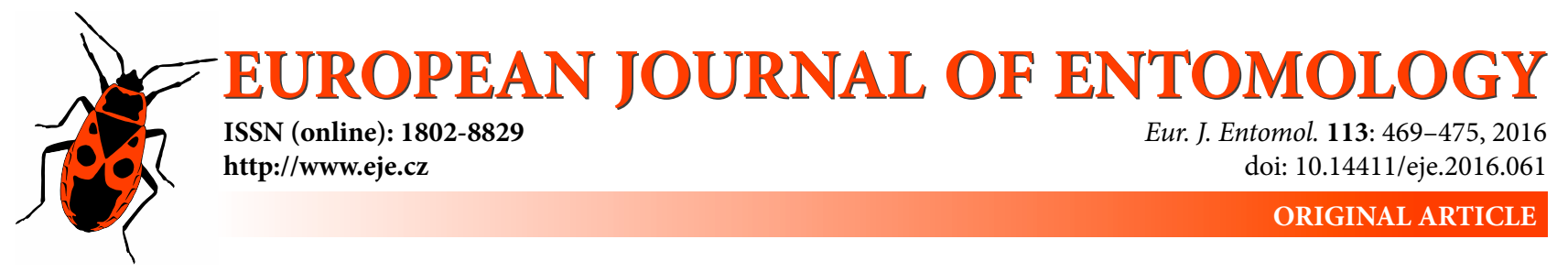

\title{
Trophic induction of diapause in native and invasive populations of Harmonia axyridis (Coleoptera: Coccinellidae)
}

\author{
Antonina A. OVChinNikoVA ${ }^{1}$, Andrey N. OVChinNIKOV ${ }^{1}$, Margarita Yu. DOLGOVSKaYA ${ }^{1}$, Sergey Ya. REZNIK ${ }^{1}$ \\ and Natalia A. BELYAKOVA ${ }^{2}$
}

${ }^{1}$ Zoological Institute, Russian Academy of Sciences, 199034 St. Petersburg, Russia; e-mails: enoty@mail.ru,
anovchi@gmail.com, bcongroup@gmail.com, reznik1952@mail.ru
${ }^{2}$ All-Russian Institute of Plant Protection, Russian Academy of Sciences, Pushkin, 196608, St. Petersburg, Russia;
e-mail: belyakovana@yandex.ru

Key words. Coleoptera, Coccinellidae, Harmonia axyridis, photoperiod, diet, diapause, invasion

\begin{abstract}
Ovipositing females from invasive (Krasnodar Territory of Russia) and native (Far East of Russia) populations of Harmonia axyridis were fed one of a set of diets ranging from 50 Myzus persicae aphids every day to 1 aphid every 10 days and all were also provided with a $10 \%$ sugar solution. The experiment was conducted at $20^{\circ} \mathrm{C}$ under short $(12 \mathrm{~h})$ and long $(18 \mathrm{~h})$ day conditions. Most of the females from the native population that consumed 50 or 10 aphids per day continued to oviposit under both long and short day conditions. Females that consumed 1 aphid per day or every 2 days practically stopped laying eggs but under long day conditions their ovaries were still active, whereas under short day conditions ca $50 \%$ of them were reproductively inactive (only germaria present) and had a well-developed fat body. Further reduction in diet resulted in an increase in the proportion of reproductively inactive females. However, about half of the females that terminated oogenesis under long day conditions had poorly developed fat bodies, which indicates that diapause was not induced. For the females from the invasive population, both photoperiodic and trophic effects were weak: under short day conditions, some females entered diapause when prey was abundant, whereas about $50 \%$ (independent of photoperiod) did not enter diapause when starved. This risk-spreading strategy, possibly, facilitates the adaptation of this invasive ladybird to unpredictable environmental conditions.
\end{abstract}

\section{INTRODUCTION}

Food is undoubtedly one of the most important environmental factors for all animals. Moreover, in some insects, it plays a double role being not only a source of nutrients but also an environmental cue regulating seasonal development. For example, feeding on wilted or senescent plants can increase the incidence of diapause in leaf beetles, moths and certain other phytophagous insects (Tauber et al., 1986). Similarly, females of some predatory ladybirds, deprived of their essential prey not only stop ovipositing but can also enter reproductive diapause, as has been demonstrated for Ceratomegilla (Semiadalia) undecimnotata Schn. (Iperti \& Hodek, 1974; Hodek, 2012), Harmonia sedecimnotata (Fabr) (Zaslavski et al., 1998; Vaghina, 2004; Reznik \& Vaghina, 2006), Hippodamia convergens Guérin (Michaud \& Qureshi, 2005, 2006) and Harmonia axyridis (Pallas) (Evans \& Gunther, 2005; Berkvens et al., 2008a; Reznik \& Vaghina, 2013). Diet can also influence the rate of reproductive maturation and fecundity in many ladybirds (Ives, 1981; Wipperfürth et al., 1987; Evans, 2000; Omkar \& Srivastava, 2003; Evans et al., 2004; Kajita \& Evans, 2009; Sharmila et al., 2009; Omkar et al., 2010;
Hodek \& Evans, 2012; Nedvěd \& Honěk, 2012; Zhang et al., 2012; Bista \& Omkar, 2014; Shah \& Khan, 2014) and, in particular, in H. axyridis (Hukusima \& Ohwaki, 1972; Schanderl et al., 1988; Abdel-Salam, 2000; Michaud, 2000; Soares et al., 2004; Tsaganou et al., 2004; Evans \& Gunther, 2005; Osawa, 2005; Soares et al., 2005; Berkvens et al., 2008a, b; Sighinolfi et al., 2008; Kögel et al., 2012; Reznik \& Vaghina, 2013; dos Santos Rodrigues et al., 2013; Reznik et al., 2015). In most of the studies cited, the "nutritional induction of diapause" is dependent on the quality of the food. The effect of prey abundance (usually measured in terms of the number of prey consumed daily) also affects the duration of the pre-oviposition period, although at the end of most of these experiments females either started to lay eggs or died rather quickly, i. e., they did not enter diapause or at least it was not recorded (Agarwala et al., 2008; Sharmila et al., 2009; Agarwala \& Bhowmik, 2011; Shah \& Khan, 2014; Bista \& Omkar, 2014). Ovipositing females of Harmonia sedecimnotata (Fabr.) transferred to a limited diet (3-6 aphids per day) continue to lay eggs, but some of those that were fed one aphid per day and all of those that were fed one aphid per 20 days 
ceased ovipositing (Vaghina, 2004). However, oogenesis can cease simply because of the absence of nutrients. Unfortunately, the second important criterion of reproductive diapause, the state of the fat body, was not recorded in the above study. Later it was demonstrated that the cessation of oviposition in $H$. sedecimnotata is associated with a marked increase in fat content, but in these experiments only two diets (high abundance and complete absence of aphids) were used (Reznik \& Vaghina, 2006). This scarcity of data indicates a need for further studies on the trophic induction of diapause in Coccinellidae associated with the abundance of prey as under natural conditions, not only high abundance and complete absence of essential species of prey, but low population densities can also occur (Dixon \& Guo, 1993; Evans, 2003; Borges et al., 2011; Hodek \& Evans, 2012).

In the present study ovipositing females of $H$. axyridis previously fed an ad libitum supply of essential prey, the green peach aphid, Myzus persicae (Sulz.), were fed a limited daily diet of the same aphids. The first aim was to compare the patterns in relatively independent trophic responses: the decrease in fecundity of ovipositing females, the termination of oogenesis, and the induction of reproductive diapause. However, $H$. axyridis is not only a convenient model insect it is also a biocontrol agent and a noxious invasive species (Koch \& Galvan, 2008; Roy \& Wajnberg, 2008; Lombaert et al., 2010; Brown et al., 2011; Sloggett, 2012; Roy et al., 2016). Recently, we demonstrated that photoperiod affects reproductive maturation of newly emerged females from native populations of $H$. axyridis much more strongly than those from invasive populations and suggested that the weak photoperiodic response could be compensated by a strong trophic response (Reznik et al., 2015). The second aim of the present study was to test this hypothesis by comparing the ranges and patterns of the trophic and photoperiodic effects on the inverse process, i.e. the induction of reproductive diapause in mature ovipositing females from native and invasive populations of $H$. axyridis. The expectation was that the trophic response of females from the invasive population would be stronger and the photoperiodic weaker than that of those from the native population.

\section{MATERIAL AND METHODS}

In this study we used two laboratory populations of $H$. axyridis. The native population originated from several tens of adults collected in 2004 in the Kedrovaya Pad' nature reserve (Khasanskiy region, Primorskiy territory, in the Far East of Russia, $43.1^{\circ} \mathrm{N}$, $131.5^{\circ} \mathrm{E}$ ). The invasive population originated from more than 120 individuals collected in 2012 at roughly the same latitude in the environs of Sochi (Krasnodar Territory of Russia, ca $43.6^{\circ} \mathrm{N}$, $39.6^{\circ} \mathrm{E}$ ). It is the first large population of $H$. axyridis found in the Caucasus and, generally, in European Russia. Most probably, it was a further eastward continuation of the invasion of this species in Europe (Belyakova \& Reznik, 2013; Ukrainsky \& Orlova-Bienkowskaja, 2014; Roy et al., 2016). Before the experiments, both strains were reared in a laboratory at a temperature of $20-25^{\circ} \mathrm{C}$ and day length of $18 \mathrm{~h}$; larvae and adults were fed on the green peach aphid, M. persicae, which was reared on broad bean, Vicia faba L., seedlings.
To prepare a replicate of the experiment, a cohort of 1st instar larvae that hatched over a period of $24 \mathrm{~h}$ from eggs laid by $20-40$ females of one of the two populations was placed in a large (12 1 , $25 \mathrm{~cm}$ tall) glass cylinder ( $70-125$ larvae per cylinder) and reared at a constant temperature of $20^{\circ} \mathrm{C}$ and day length of $18 \mathrm{~h}$. Food (M. persicae on bean seedling) was provided daily. The adults that emerged were kept under the same conditions (60-95 beetles per cylinder) for 20-25 days. Then the beetles were sexed, females were placed individually in plastic Petri dishes $(60 \times 15$ $\mathrm{mm}$ ), kept under the same conditions, and periodically checked for oviposition (only egg-laying females were used in the experiment).

For the experiment, randomly selected Petri dishes with egglaying females were evenly distributed over 12 treatments, i.e. combinations of two photoperiods (day lengths of 12 and $18 \mathrm{~h}$ ) and six diets differing in the daily number of aphids provided: 0 (no aphids), 1 aphid every 10 days, 1 aphid every 2 days, 1 aphid every day, 10 aphids every day and about 50 aphids every day. Each diet also included a 10\% sugar solution provided in an Eppendorf tube plugged with cotton wool. Aphids were offered on bean seedling, but when the insects were kept without aphids, they were still provided with a bean seedling, which was replaced every 2 days. The number of eggs laid by each female was recorded daily. Forty days after the beginning of the experiment all females were dissected to record their reproductive state: "reproductively inactive" (only germaria present, follicles absent, no visible oocytes) or "reproductively active" (stage I-II follicles or mature oocytes present). The state of the fat body was recorded as "poorly developed" (thin lobes interspersed around the internal organs) or "well developed" (well-formed globules and interconnected lobes, the internal organs completely or nearly completely hidden). Thus, for each treatment and replicate the proportion of females with ovaries and fat bodies in the different stages of development were calculated. Fecundity was also estimated for each treatment and replicate as the mean number of eggs laid daily per female. Two indices of fecundity were used: the mean fecundity over the first 10 days of the experiment was calculated for all females, whereas the mean fecundity from the 11th -40 th day of the experiment was calculated only for the females that were classed as reproductively active when dissected.

There were never less than 4 (usually 5) females in each replicate of each of the 12 treatments. There were 5 replicates (total of 307 females) of the beetles from the native Far Eastern population and 5 replicates (total of 347 females) of the beetles from the invasive population from Sochi. The replicates were started with different cohorts of larvae at intervals of at least several days. In addition, different replicates were conducted in different chambers of the thermostatic room. Thus, the replicates were separated both in time and space. For the statistical treatment, ANOVA followed by Tukey's HSD test was used (before the treatment, proportions were ranked). All calculations were made using SYSTAT 10.2 (Systat Software, Inc., San Jose, CA).

\section{RESULTS}

Adult survival over the 40 days of the experiment was high (ca 96\% for the pooled data) and was independent of photoperiod, diet and origin of the beetles (three-way ANOVA showed $p>0.1$ for all three factors and their interactions). The proportion of reproductively inactive females was significantly dependent on both photoperiod and diet; the interaction of these two factors was also significant indicating that the pattern of the trophic response to some extent depended on photoperiod (Table 1). The difference 

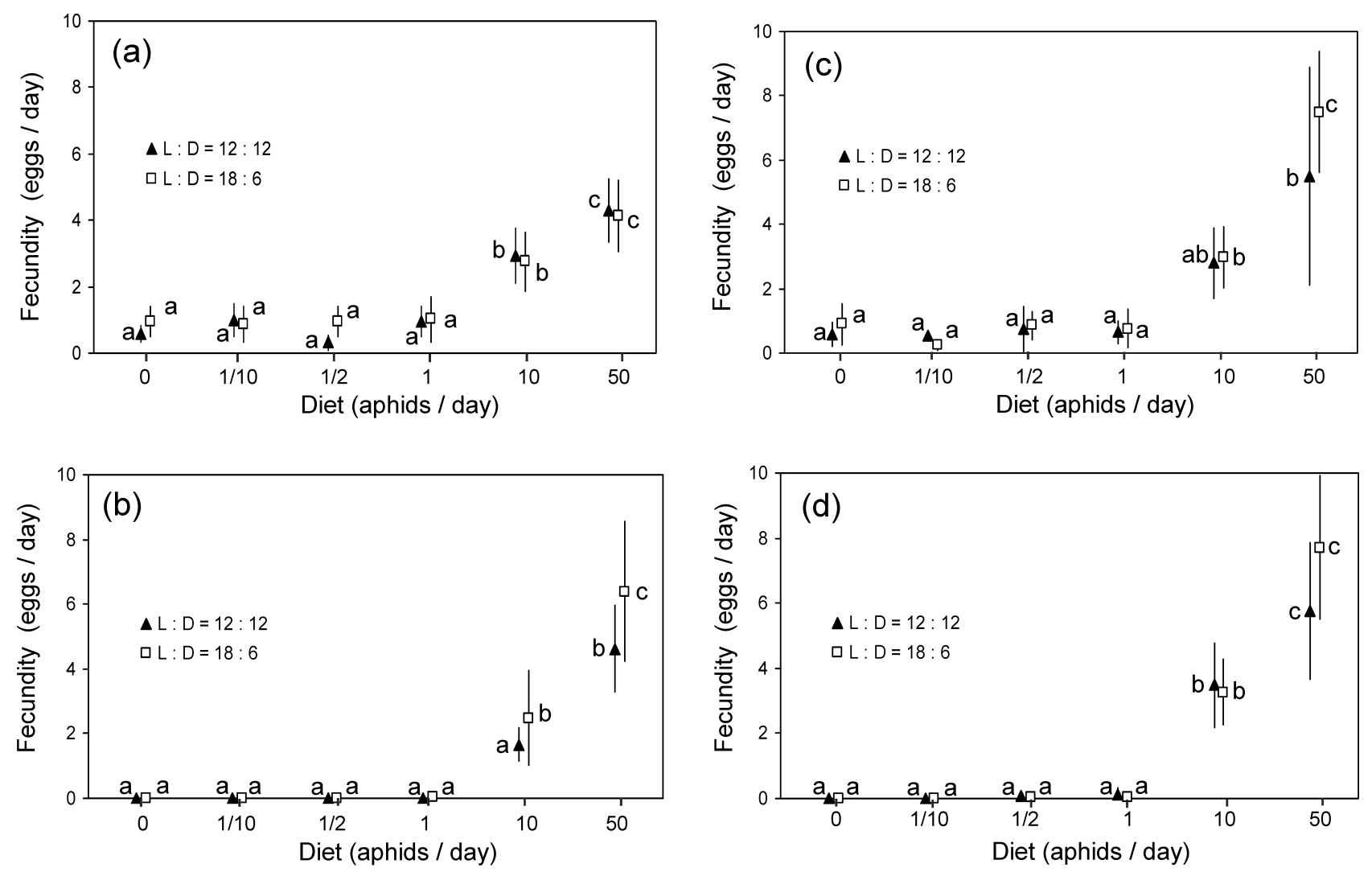

Fig. 1. Influence of photoperiod and diet on fecundity of reproductively active females in two populations of Harmonia axyridis. Populations: (a) and (b) - native (Kedrovaya Pad'), (c) and (d) - invasive (Sochi). Fecundity was estimated: (a) and (c) - over the first 10 days of the experiment, (b) and (d) - between 11th-40th day of the experiment. Means and SD are shown. Same symbols with different letters are significantly different $(p<0.05$ with the Tukey HSD test).

between the two populations was not significant, but the interaction of the factors "photoperiod" and "population" was significant. In other words, populations differed not in the general tendency to diapause but in the pattern of the photoperiodic response. These photo-trophic responses of females of the two different origins were also somewhat different, which is indicated by the significant interaction between the factors "photoperiod", "diet" and "population". The mean daily fecundity of active (ovipositing) females was significantly dependent on diet but not on day length or origin of the beetles (Table 1). Both during the first 10 days (Fig. 1a and c) and the rest of the experiment (Fig. $1 \mathrm{~b}$ and d) females that consumed not more than one aphid per day had the same fecundity as those that were only provided with sugar solution.
When data for the females of the two different origins were considered separately, diet had a significant effect on the proportion of reproductively inactive females recorded for the native population (Fig. 2a). Moreover, the pattern in the trophic response depended on photoperiod (note the difference between the threshold diets) and the difference between the two photoperiods was significant for almost all the diets (Fig. 2a). In the females from the invasive population, both photoperiodic and trophic effects on the proportion of reproductively inactive females were also statistically significant, but less so (Fig. 2b).

A photoperiodic effect on the development of the fat body in females from the native population was significant (Fig. 3a), whereas no trophic effect was detected. In contrast, there was no photoperiodic effect on the development

Table 1. Influence of photoperiod and diet on reproductive activity of females from native and invasive populations of Harmonia axyridis (the results of a three-way ANOVA of the entire data set).

\begin{tabular}{lccc}
\hline Factor or interaction of factors & $\begin{array}{c}\text { The proportion of reproductively } \\
\text { inactive females }(n=120)\end{array}$ & $\begin{array}{c}\text { The mean daily fecundity } \\
\text { over the first } 10 \text { days of the } \\
\text { experiment }(n=120)\end{array}$ & $\begin{array}{c}\text { The mean daily fecundity } \\
\text { of reproductively active females } \\
\text { over the period from the 11th-40th } \\
\text { day of the experiment }(n=107)\end{array}$ \\
\hline Photoperiod $(d f=1)$ & $F=91.7, p<0.001$ & $F=2.0, p=0.160$ & $F=2.7, p=0.107$ \\
Diet $(d f=5)$ & $F=44.9, p<0.001$ & $F=70.7, p<0.001$ & $F=105.1, p<0.001$ \\
Population $(d f=1)$ & $F=0.6, p=0.456$ & $F=2.0, p=0.164$ & $F=4.2, p=0.044$ \\
Photoperiod ${ }^{*}$ population $(d f=1)$ & $F=7.4, p=0.008$ & $F=0.7, p=0.407$ & $F=0.1, p=0.704$ \\
Diet $^{*}$ population $^{(}(f=5)$ & $F=2.1, p=0.072$ & $F=4.9, p<0.001$ & $F=1.6, p=0.159$ \\
Phoperiod $^{*}$ diet $(d f=5)$ & $F=3.7, p=0.004$ & $F=0.7, p=0.590$ & $F=2.5, p=0.039$ \\
Photoperiod $^{*}$ diet $^{*}$ population $(d f=5)$ & $F=4.0, p=0.002$ & $F=1.1, p=0.358$ & $F=0.2, p=0.956$ \\
\hline
\end{tabular}



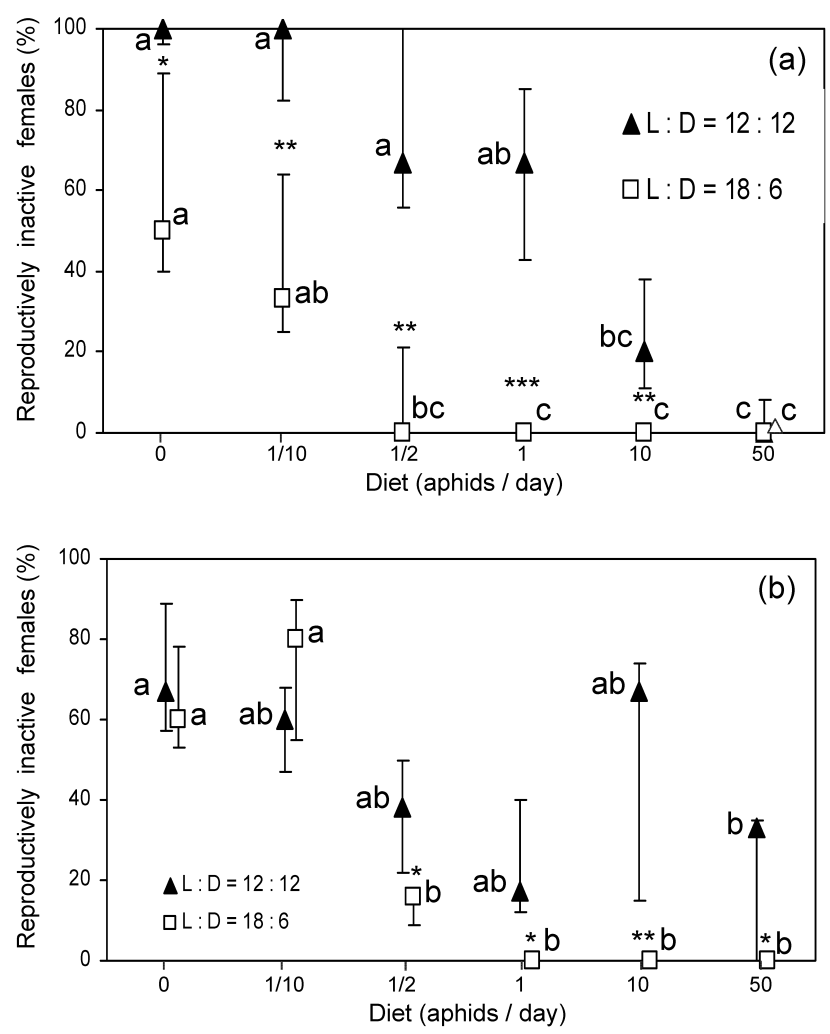

Fig. 2. Influence of photoperiod and diet on the percentage of reproductively inactive females in two populations of Harmonia axyridis. Populations: (a) - native (Kedrovaya Pad'), (b) - invasive (Sochi). Photoperiod (Light: Dark) is indicated on the graphs. Medians and quartiles are shown. Asterisks indicate significant difference between the ranked data for the two photoperiods: * $-p$ $<0.05,{ }^{* *}-p<0.01,{ }^{* * *}-p<0.001$. Same symbols with different letters are significantly different $(p<0.05$ with the Tukey HSD test of ranked data).

of the fat body in females from the invasive population, whereas the trophic effect, at least under short day conditions, was statistically significant (Fig. 3b). Note that under long day conditions the proportion of females with a welldeveloped fat body (among those with non-functioning ovaries) was estimated only for the three poorest diets (Fig. 3 ) because reproductively inactive females did not occur in treatments combining long days and relatively rich diets (Fig. 2). As for the females with active ovaries, very few of them (ca 5\%) had well-developed fat bodies and this was independent of photoperiod and diet.

\section{DISCUSSION}

First, the $H$. axyridis females fed one aphid per day and less laid the remainder of the eggs that were in their ovaries at the beginning of the experiment and then ceased laying eggs. It is well known that ladybird females deprived of their essential food cease laying eggs. Moreover, oviposition is one criterion of an essential prey (Hodek \& Evans, 2012; Nedvěd \& Honěk, 2012). However, most of the experiments on this subject are qualitative: females were either starved or provided ad libitum with different diets (e.g. Evans et al., 2004; Evans \& Gunther, 2005; Osawa, 2005; Sighinolfi et al., 2008; Kögel et al., 2012; Zhang et al., 2012). Quantitative studies have usually been on the cor-
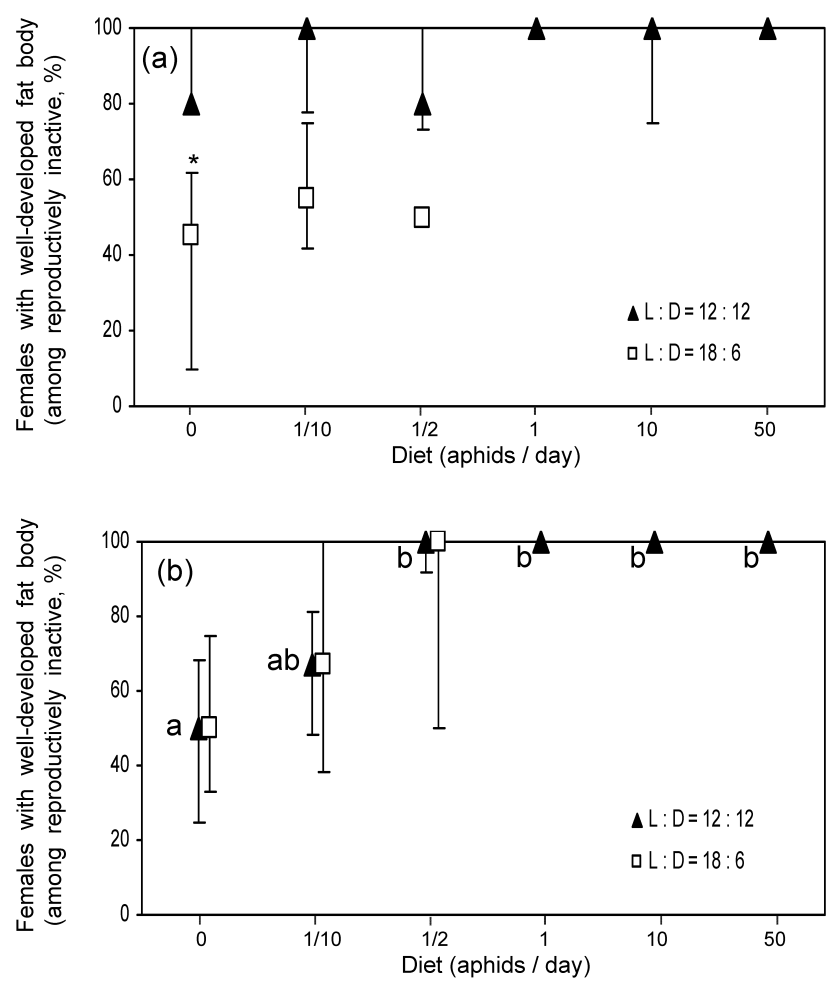

Fig. 3. Influence of photoperiod and diet on the percentage of reproductively inactive females with a well-developed fat body in two populations of Harmonia axyridis. Populations: (a) - native (Kedrovaya Pad'), (b) - invasive (Sochi). Photoperiod (Light: Dark) is indicated on the graphs. Medians and quartiles are shown. Asterisk indicates significant difference between the ranked data for the two photoperiods: ${ }^{*}-p<0.05$. Same symbols with different letters are significantly different $(p<0.05$ with the Tukey HSD test of ranked data); the absence of letters means the absence of any significant difference.

relation between the number of prey consumed and the rate of maturation or the number of eggs laid and thus near-zero diets have not been tested (Sharmila et al., 2009; Omkar et al., 2010; Shah \& Khan, 2014). Nevertheless, the "low trophic threshold" of $H$. axyridis females was estimated by Agarwala \& Bhowmik (2011) as ca 3 aphids per female (i.e. higher than that recorded in this study): individuals offered 2 aphids did not mature and died within 2-3 weeks. Note that in the above cited experiments ladybirds were not provided with any alternative food and therefore were not able to enter reproductive diapause, whereas in nature various sources of carbohydrate food (flowers, fruits, damaged plants, etc.), in contrast to aphids, are usually available throughout summer (Berkvens et al., 2008b; Borges et al., 2011; Hodek \& Evans, 2012).

The observed termination of oviposition does not necessarily imply the induction of reproductive diapause: dissections of H. axyridis females from the native Far Eastern population showed that a substantial fraction of ladybirds that consumed one aphid a day under short-day conditions and all of those fed on the same diet under long-day conditions had active ovaries and a poorly developed fat body. Further reduction in diet induced a clear dose-dependent effect on the proportion of reproductively inactive females. Similar results are reported by Vaghina (2004) for $\mathrm{H}$. se- 
decimnotata: a decrease in the number of aphids consumed daily from 6 to 1 resulted in a corresponding decrease in fecundity, whereas extremely poor rations of 1 aphid per 12 and per 20 days caused a cessation of oogenesis in, 44 and $93 \%$ of the females, respectively. Unfortunately, the state of the fat body was not recorded in these experiments and thus it is not clear whether it was merely cessation of oogenesis or "true" reproductive diapause. Furthermore, all experiments were conducted under constant light (Vaghina, 2004) whereas our results indicate that there is an interaction between the trophic and photoperiodic responses: note, in particular, the shift in the threshold similar to that often observed in photoperiod-temperature interactions (Tauber et al., 1986; Zaslavski, 1988; Saunders et al., 2002). Thus, we have for the first time for Coccinellidae described the patterns of two quantitative trophic responses of mature females: (1) termination of egg-laying and (2) induction of reproductive diapause under different photoperiods.

Summarizing the results, the photo-trophic responses of actively ovipositing females from the native Far Eastern population of $H$. axyridis can be described as follows: most females that consumed 10 or more aphids per day continued oviposition independent of photoperiod. On poorer diets ( 1 aphid per day or per two days) females practically stop laying eggs, but under long day conditions their ovaries remain active, whereas under short days about half of the individuals become inactive (only germaria present). Moreover, under the latter conditions, almost all reproductively inactive females have a well-developed fat body, indicating they are in reproductive diapause. Any further reduction in diet results in a further increase in the proportion of reproductively inactive females. However, about half the females that ceased oogenesis under long day conditions had a poorly developed fat body, indicating that reproductive diapause was not induced in these individuals.

In the field, the above results indicate that females of $H$. axyridis cease oviposition when they consume less than one essential prey per day (considering their high activity and search ability, this would correspond to a very low prey population density). If this period of prey shortage occurs in summer, most females terminate oviposition without entering reproductive diapause (fat and glycogen reserves are not as necessary for survival during summer aestivation when alternative food sources are available). In autumn, however, the same decrease in prey density is associated with a significant increase in fat body size, which can be inferred as a preparation for overwintering.

With regard to the second aim of the present study, we conclude that our working hypothesis was only partly confirmed. In the invasive population, both photoperiodic and trophic effects on the proportion of reproductively inactive females were much weaker than in the native population. Moreover, in the invasive population the proportion of "truly diapausing" individuals (i.e. those with a well-developed fat body) among reproductively inactive females was practically independent of photoperiod. In an earlier study, we report a relatively weak photoperiodic response in maturing (newly emerged) females from invasive popu- lations (Reznik et al., 2015). In the present study, the same feature is shown for the inverse process: induction of diapause in mature ovipositing females. However, contrary to our earlier supposition, the trophic effect on the proportion of reproductively inactive females in the invasive population is also relatively weak and less clear than in the native population. This interpopulation difference is particularly marked under short-day conditions: comparison of Figs $2 b$ and $3 \mathrm{~b}$ indicates that in autumn about $40 \%$ of the females of the invasive population terminate oviposition and enter diapause even when prey is abundant but, on the other hand, even in the complete absence of prey, about half of the females terminate oviposition, but there is no increase in the size of their fat body, i. e., they do not enter diapause. Such a response, as well as oosorption during starvation and immediate start of ovarian development under favourable feeding conditions (Osawa, 2005) is probably an adaptation to fluctuating prey abundance. In addition, this phenomenon, as well as a weak photoperiodic response (Reznik et al., 2015) and other manifestations of high individual variability (Sloggett, 2012; Roy et al., 2016) can be interpreted as a risk-spreading strategy (Hopper, 1999) that ensures the survival of at least some individuals of the invasive population under novel and unpredictable environmental conditions.

ACKNOWLEDGEMENTS. We thank O.S. Bezman-Moseyko, T.Yu. Moskaleva and L.S. Ramenskaya (Zoological Institute RAS) for their excellent technical assistance. We greatly appreciate the useful comments on our manuscript of two anonymous reviewers. This work was partly supported by the Russian Foundation for Basic Research (grant \# 15-29-02526 "Integrative study of biological invasions and anthropogenic impact on ecosystems") and the State project \# 52 "Morphological and ecophysiological adaptations of insects as a component of biodiversity" (state registration \# 01201351183).

\section{REFERENCES}

Abdel-Salam A.H. 2000: Biological and life table studies of Harmonia axyridis Pallas (Coleoptera: Coccinellidae) reared on the factitious prey, Sitotroga cerealella Olivier (Lepidoptera: Gelechiidae). - Pakistan J. Biol. Sci. 3: 580-585.

Agarwala B.K. \& Bhowmik P.J. 2011: Effect of resource gradient on age and size at maturity and their influence on early-life fecundity in the predatory Asian lady beetle, Harmonia axyridis. —Entomol. Exp. Appl. 141: 97-102.

Agarwala B.K., Yasuda H. \& Sato S. 2008: Life history response of a predatory ladybird, Harmonia axyridis (Pallas) (Coleoptera: Coccinellidae), to food stress. - Appl. Entomol. Zool. 43: 183-189.

BelYaKova N.A. \& REZnIK S.YA. 2013: First record of the harlequin ladybird, Harmonia axyridis (Coleoptera: Coccinellidae) in the Caucasus. - Eur. J. Entomol. 110: 699-702.

Berkvens N., Bonte J., Berkvens D., Tirry L. \& De ClercQ P. 2008a: Influence of diet and photoperiod on development and reproduction of European populations of Harmonia axyridis (Pallas) (Coleoptera: Coccinellidae). - BioControl 53: 211-221.

Berkvens N., Bonte J., Berkvens D., Deforce K., Tirry L. \& De ClercQ P. 2008b: Pollen as an alternative food for Harmonia axyridis. - BioControl 53: 201-210. 
Bista M. \& OMKAR 2014: Consumption, developmental and reproductive attributes of two con-generic ladybird predators under variable prey supply. - Biol. Contr. 74: 36-44.

Borges I., Soares A.O., Magro A. \& Hemptinne J.L. 2011: Prey availability in time and space is a driving force in life history evolution of predatory insects. - Evol. Ecol. 25: 1307-1319.

Brown P.M.J., Thomas C.E., Lombaert E., Jeffries D.L., Estoup A. \& Handley L.J.L. 2011: The global spread of Harmonia axyridis (Coleoptera: Coccinellidae): distribution, dispersal and routes of invasion. - BioControl 56: 623-641.

Dixon A.F.G. \& Guo Y. 1993: Egg and cluster size in ladybird beetles (Coleoptera: Coccinellidae): The direct and indirect effects of aphid abundance. - Eur. J. Entomol. 90: 457-463.

Evans E.W. 2000: Egg production in response to combined alternative foods by the predator Coccinella transversalis. - Entomol. Exp. Appl. 94: 141-147.

Evans E.W. 2003: Searching and reproductive behaviour of female aphidophagous ladybirds (Coleoptera: Coccinellidae): a review. - Eur. J. Entomol. 100: 1-10.

Evans E.W. \& GunThER D.I. 2005: The link between food and reproduction in aphidophagous predators: a case study with Harmonia axyridis (Coleoptera: Coccinellidae). — Eur. J. Entomol. 102: 423-430.

Evans E.W., Richards D.R. \& Kalaskar A. 2004: Using food for different purposes: female responses to prey in the predator Coccinella septempunctata L. (Coleoptera: Coccinellidae). - Ecol. Entomol. 29: 27-34.

Hodek I. 2012: Diapause / Dormancy. In Hodek I., van Emden H.F. \& Honěk A. (eds): Ecology and Behaviour of the Ladybird Beetles (Coccinellidae). Wiley-Blackwell, Chichester, pp. 275-342.

HodeK I. \& Evans E.W. 2012: Food Relationships. In Hodek I., van Emden H.F. \& Honěk A. (eds): Ecology and Behaviour of the Ladybird Beetles (Coccinellidae). Wiley-Blackwell, Chichester, pp. 141-274.

HoPper K.R. 1999: Risk-spreading and bet-hedging in insect population biology. - Annu. Rev. Entomol. 44: 535-560.

Hukusima S. \& OHWAкI T. 1972: Further notes on feeding biology of Harmonia axyridis Pallas (Coleoptera: Coccinellidae). — Res. Bull. Fac. Agric. Gifu Univ. 33: 75-82.

IPERTI G. \& HODEK I. 1974: Induction alimentaire de la dormance imaginale chez Semiadalia undecimnotata Schn. (Coleop. Coccinellidae) pour aider à la conservation des coccinelles élevées au laboratoire avant une utilisation ultérieure. - Ann. Zool. Ecol. Anim. 6: 41-51.

IVES P.M. 1981: Feeding and egg production of two species of coccinellids in the laboratory. — Can. Entomol. 113: 999-1005.

KaJITA Y. \& Evans E.W. 2009: Ovarian dynamics and oosorption in two species of predatory lady beetles (Coleoptera: Coccinellidae). - Physiol. Entomol. 34: 185-194.

Koch R.L. \& Galvan T.L. 2008: Bad side of a good beetle: the North American experience with Harmonia axyridis. - BioControl 53: 23-35.

Kögel S., Eben A., Hoffmann C. \& Gross J. 2012: Influence of diet on fecundity, immune defense and content of 2-isopropyl3-methoxypyrazine in Harmonia axyridis Pallas. - J. Chem. Ecol. 38: 854-864.

Lombaert E., Guillemaud T., Cornuet J.M., Malausa T., Facon B. \& Estoup A. 2010: Bridgehead effect in the worldwide invasion of the biocontrol harlequin ladybird. - PLOS ONE 5(3):e9743, $7 \mathrm{pp}$.

Michaud J.P. 2000: Development and reproduction of ladybeetles (Coleoptera: Coccinellidae) on the citrus aphids Aphis spiraecola Patch and Toxoptera citricida (Kirkaldy) (Homoptera: Aphididae). - Biol. Contr. 18: 287-297.
Michaud J.P. \& QURESHI J.A. 2005: Induction of reproductive diapause in Hippodamia convergens (Coleoptera: Coccinellidae) hinges on prey quality and availability. - Eur. J. Entomol. 102: 483-487.

Michaud J.P. \& QURESHI J.A. 2006: Reproductive diapause in Hippodamia convergens (Coleoptera: Coccinellidae) and its life history consequences. - Biol. Contr. 39: 193-200.

NedVĚD O. \& HoNĚK A. 2012: Life history and development. In Hodek I., van Emden H.F. \& Honěk A. (eds): Ecology and Behaviour of the Ladybird Beetles (Coccinellidae). Wiley-Blackwell, Chichester, pp. 54-109.

OMKAR \& SRIVASTAVA S. 2003: Influence of six aphid prey species on development and reproduction of a ladybird beetle, Coccinella septempunctata. - Biol. Contr. 48: 379-393.

OmKar, SAhu J. \& Kumar G. 2010: Effect of prey quantity on reproductive and developmental attributes of a ladybird beetle, Anegleis cardoni. - Int. J. Trop. Insect Sci. 30: 48-56.

OSAWA N. 2005: The effect of prey availability on ovarian development and oosorption in the ladybird beetle Harmonia axyridis (Coleoptera: Coccinellidae). — Eur. J. Entomol. 102: 503-511.

ReZnik S.YA. \& Vaghina N.P. 2006: Dynamics of fat content during induction and termination of "trophic diapause" in Harmonia sedecimnotata Fabr. females (Coleoptera, Coccinellidae). - Entomol. Rev. 86: 125-132.

REZnIK S.YA. \& VAGHINA N.P. 2013: Effects of photoperiod and diet on diapause tendency, maturation and fecundity in Harmonia axyridis (Coleoptera: Coccinellidae). - J. Appl. Entomol. 137: 452-461.

Reznik S.Ya., Dolgovskaya M.Yu., Ovchinnikov A.N. \& BelyaKOVA N.A. 2015: Weak photoperiodic response facilitates the biological invasion of the harlequin ladybird Harmonia axyridis (Pallas) (Coleoptera: Coccinellidae). - J. Appl. Entomol. 139: 241-249.

Roy H. \& WaJNBerg E. 2008: From biological control to invasion: the ladybird Harmonia axyridis as a model species. BioControl 53: 1-4.

Roy H.E., Brown P.M., Adriaens T., Berkvens N., Borges I., Clusella-Trullas S., Comont R.F., De Clerce P., Eschen R., Estoup A. ET AL. 2016: The harlequin ladybird, Harmonia axyridis: global perspectives on invasion history and ecology. - Biol. Invas. 18: 997-1044.

Santos Rodrigues A.R. dos, Spíndola A.F., de Morais Oliveira J.E. \& ToRres J.B. 2013: Dietary effects upon biological performance and lambda-cyhalothrin susceptibility in the multicolored Asian lady beetle, Harmonia axyridis. — Phytoparasitica 41: 285-294.

Saunders D.S., Steel C.G.H., Vafopoulou X. \& Lewis R.D. 2002: Insect Clocks. Elsevier, Amsterdam, 560 pp.

Schanderl H., Ferran A. \& Garcia V. 1988: L'élevage de deux coccinelles Harmonia axyridis et Semiadalia undecimnotata à l'aide d'oeufs d'Anagasta kuehniella tués aux rayons ultraviolets. - Entomol. Exp. Appl. 49: 235-244.

SHAн M.A. \& KHAN A.A. 2014: Qualitative and quantitative prey requirements of two aphidophagous coccinellids, Adalia tetraspilota and Hippodamia variegata. - J. Insect Sci. 14: 72, $19 \mathrm{pp}$.

Sharmila M., Lokeshwari R.K., Singh T.K. \& Agarwala B.K. 2009: Effect of different prey densities on the reproductive attributes of Harmonia dimidiata (Fabricius) (Coleoptera: Coccinellidae). - Entomon 34: 23-27.

Sighinolfi L., Febvay G., Dindo M.L., Rey M., Pageaux J., BaroNIO P. \& GRENIER S. 2008: Biological and biochemical characteristics for quality control of Harmonia axyridis (Pallas) (Co- 
leoptera, Coccinellidae) reared on a liver-based diet. - Arch. Insect Biochem. Physiol. 68: 26-39.

Sloggett J.J. 2012: Harmonia axyridis invasions: Deducing evolutionary causes and consequences. - Entomol. Sci. $\mathbf{1 5}$ 261-273.

SoAres A.O., Coderre D. \& Schanderl H. 2004: Dietary selfselection behaviour by the adults of the aphidophagous ladybeetle Harmonia axyridis (Coleoptera: Coccinellidae). $-J$. Anim. Ecol. 73: 478-486.

Soares A.O., Coderre D. \& Schanderl H. 2005: Influence of prey quality on the fitness of two phenotypes of Harmonia axyridis adults. - Entomol. Exp. Appl. 114: 227-232.

Tauber M.J., Tauber C.A. \& Masaki S. 1986: Seasonal Adaptations of Insects. Oxford University Press, New York, 411 pp.

Tsaganou F.C., Hodgson C.J., Athanassiou C.G., Kavallieratos N.G. \& Tomanović Ž. 2004: Effect of Aphis gossypii Glover, Brevicoryne brassicae (L.), and Megoura viciae Buckton (Hemiptera: Aphidoidea) on the development of the predator Harmonia axyridis (Pallas) (Coleoptera: Coccinellidae). - Biol. Contr. 31: 138-144.
Ukrainsky A.S. \& Orlova-Bienkowskaja M.J. 2014: Expansion of Harmonia axyridis Pallas (Coleoptera: Coccinellidae) to European Russia and adjacent regions. - Biol. Invas. 16: $1003-1008$

VAGHina N.P. 2004: Trophic diapause in the tropical coccinellid Harmonia sedecimnotata (Fabr.) (Coleoptera, Coccinellidae): induction and reactivation. - Entomol. Rev. 84: 389-392.

Wipperfürth T., Hagen K.S. \& Mittler T.E. 1987: Egg production by the coccinellid Hippodamia convergens fed on two morphs of the green peach aphid, Myzus persicae. - Entomol. Exp. Appl. 44: 195-198.

ZASlavsKi V.A. 1988: Insect Development: Photoperiodic and Temperature Control. Springer, New York, $187 \mathrm{pp}$.

Zaslavski V.A., Sem'yanov V.P. \& Vagina N.P. 1998: Food as a cue factor controlling adult diapause in the lady beetle Harmonia sedecimnotata (Coleoptera, Coccinellidae). - Entomol. Rev. 78: 774-779.

Zhang S.Z., Li J.J., Shan H.W., Zhang F. \& Liu T.X. 2012: Influence of five aphid species on development and reproduction of Propylea japonica (Coleoptera: Coccinellidae). - Biol. Contr. 62: 135-139.

Received May 10, 2016; revised and accepted August 3, 2016 Published online September 5, 2016 